\title{
Pengembangan Co-Tidal Charts Untuk Analisis Karakteristik Pasang Surut Perairan Laut Jawa
}

\author{
Andyra Yahya Nugraha Putra, dan Danar G. Pratomo \\ Departemen Teknik Geomatika, Fakultas Teknik Sipil dan Perencanaan, Institut Teknologi Sepuluh \\ Nopember \\ e-mail: andyra13@mhs.geodesy.its.ac.id,guruh@geodesy.its.ac.id
}

\begin{abstract}
Abstrak-Penelitian ini merupakan pengembangan Co-Tidal Charts di Laut Jawa untuk mendapatkan gambaran perambatan pasang surut di area tersebut. Data prediksi pasang surut dihitung dengan analisis harmonik dari dua puluh stasiun pengamatan pasut yang tersebar di perairan Laut Jawa dan digunakan untuk membuat Co-Tidal Charts tersebut. Konstanta harmonik pasut diolah menggunakan metode least square. Pada penelitian ini menggunakan lima konstanta harmonik yang digunakan untuk membentuk Co-Tidal Charts yaitu $\mathrm{M}_{2}, \mathrm{~N}_{2}, \mathrm{~S}_{2}, \mathrm{~K}_{1}$ dan $\mathrm{O}_{1}$. Co-Tidal Charts yang diperoleh menunjukkan gambaran secara umum karakteristik pasang surut di perairan Laut Jawa termasuk area persebaran tipe pasut dan arah rambatan pasut. Berdasarkan penelitian ini arah rambatan gelombang pasut Laut Jawa berasal dari Samudera Hindia dan Laut China Selatan melalui Selat Karimata yang bertemu di tengah Laut Jawa. Perairan Laut Jawa pada bagian Barat dan Tengah didominasi oleh komponen pasut harian (diurnal) dan bagian Timur didominasi komponen pasut setengah harian (semidiurnal). Kondisi tersebut yang mempengaruhi variasi tipe pasut di perairan Laut Jawa.
\end{abstract}

Kata Kunci-Co-Tidal Charts, Laut Jawa, Perambatan Pasut.

\section{PENDAHULUAN}

$\mathrm{L}$ AUT Jawa merupakan daerah perairan yang terletak di

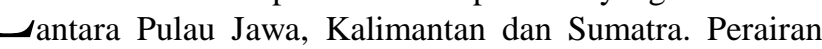
tersebut mempunyai berbagai macam potensi sumber daya alam baik hayati dan non hayati. Dengan berbagai potensi yang terkandung di dalamnya dan sebagai alur pelayaran yang padat maka dibutuhkan pemahaman akan fenomena alam yang terdapat di perairan tersebut. Hal ini berguna untuk mendukung upaya pemanfaatan sumber daya laut dan berbagai kegiatan lain yang terdapat di perairan tersebut. Salah satu fenomena alam di laut yang harus dipahami adalah perubahan elevasi muka air laut atau yang biasa disebut pasang surut air laut.

Pasang surut (pasut) air laut memiliki sifat yang dinamis dan masing-masing daerah memiliki karakteristik pasut yang berbeda, Untuk memahami sifat dan karakteristik tersebut diperlukan adanya suatu informasi akan karakteristik pasut dalam bentuk peta. Hal ini dimaksudkan agar berbagai pihak bisa memahami, menggunakan dan memanfaatkan potensi yang terdapat pada perairan laut.

Peta pasang surut atau Co-Tidal Charts menginformasikan data pasut secara spasial. Peta pasut terdiri dari peta Co-Amplitude dan peta Co-Phase. Peta CoAmplitude menyajikan informasi amplitudo dan Co-Phase menyajikan informasi fase masing-masing konstanta harmonik mengenai karakteristik pasut yang disajikan dalam garis-garis kontur.

Penelitian ini dimaksudkan untuk membuat Co-Tidal Charts di Laut Jawa menggunakan data prediksi pasang surut dari dua puluh stasiun pengamatan pasut yang tersebar di Laut Jawa. Data pengamatan pasut diperoleh dari Pusat Hidro-Oseanografi TNI AL. Penelitian ini menggunakan lima konstanta pasut harmonik yang terdiri dari tiga konstanta pasut semidiurnal $\left(\mathrm{M}_{2}, \mathrm{~N}_{2}\right.$ dan $\left.\mathrm{S}_{2}\right)$ dan dua konstanta pasut diurnal $\left(\mathrm{K}_{1}\right.$ dan $\left.\mathrm{O}_{1}\right)$. Analisis yang dilakukan pada penelitian ini menggunakan metode least square atau perataan kuadrat terkecil.

\section{METODOLOGI PENELITIAN}

\section{A. Lokasi Penelitian}

Lokasi yang menjadi penelitian ini adalah Perairan Laut Jawa, dengan letak geografis $2^{\circ} 27^{\prime} 35,21^{\prime \prime}-8^{\circ} 23^{\prime} 0,26^{\prime \prime}$ LS dan $105^{\circ} 49^{\prime} 9,76^{\prime \prime}-119^{\circ} 41^{\prime} 44^{\prime \prime}$ BT.

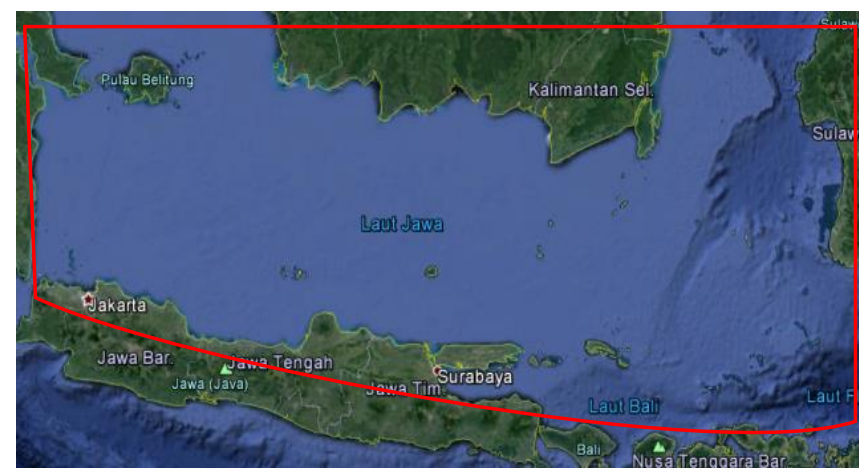

Gambar 1. Lokasi Penelitian

\section{B. Data dan Peralatan yang Digunakan}

Dalam penelitian ini menggunakan data prediksi dua puluh stasiun pengamatan pasut satu bulan (bulan Januari) tahun 2017 dengan lokasi stasiun terlampir, garis pantai Perairan Laut Jawa (NOAA) dan batimetri global tahun 2014 (GEBCO). Adapun peralatan yang digunakan yakni Matlab, Surfer, Global Mapper dan ArcMap.

\section{Tahapan Penelitian}

Dalam penelitian ini dijelaskan proses tahap persiapan dan pengolahan data untuk membuat co-tidal charts Perairan Laut Jawa.

\section{1) Tahap Persiapan}

Pada tahap persiapan dilakukan pemasukan data pasang surut dua puluh stasiun dan transformasi koordinat stasiun 
pasut ke proyeksi Mercator. Selanjutnya pemilihan area batimetri untuk kontur kedalaman dan pemilihan garis pantai.

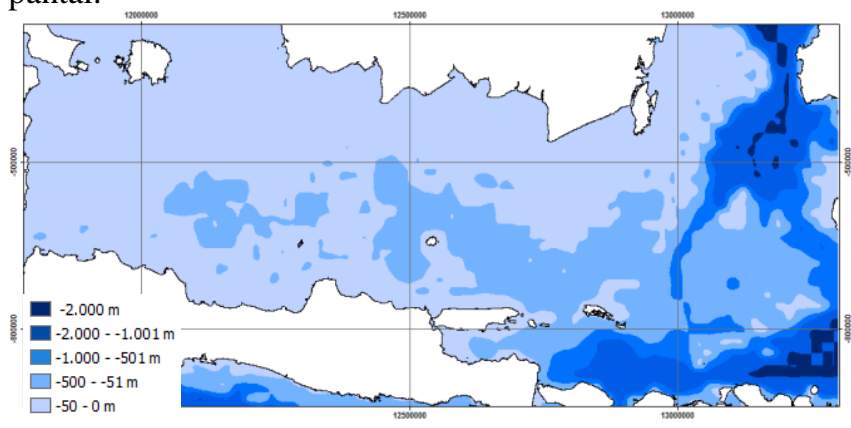

Gambar 2.Garis pantai dan kedalaman perairan Laut Jawa

\section{2) Tahap Pengolahan Data}

Pada pembuatan Co-Tidal Charts dilakukan analisis konstanta harmonik $\mathrm{M}_{2}, \mathrm{~N}_{2}, \mathrm{~S}_{2}, \mathrm{~K}_{1}$ dan $\mathrm{O}_{1}$ menggunakan metode least square serta penghitungan nilai Formzahl dengan perangkat lunak Matlab. Persamaan perhitungan pasut secara umum [1]:

$$
\begin{aligned}
& H(t)_{i}=A_{0}+\sum_{1}^{n} A_{n} \cos \left[\varpi_{n} t_{i}-g_{n}\right] \\
& \text { Formzahl }=\frac{K_{1}+O_{1}}{M_{2}+S_{2}} \\
& j_{n}=\frac{g_{n}}{\omega_{n}}
\end{aligned}
$$

dimana:

$$
\begin{array}{ll}
H_{(t)} & =\text { tinggi muka air laut saat } \mathrm{t} \\
A_{0} & =\text { tinggi muka air laut rata-rata } \\
A_{n} & =\text { amplitudo konstanta pasut ke-n } \\
\omega_{n} & =\text { kecepatan sudut konstanta pasut ke-n } \\
\mathrm{g}_{n} & =\text { fase konstanta pasut ke-n } \\
t_{i} & =\text { jumlah lama pengamatan } \\
n & =\text { jumlah konstanta pasut } \\
j_{n} & =\text { waktu air tinggi (jam) }
\end{array}
$$

Selanjutnya hasil dari penghitungan yang berupa nilai amplitudo, fase dan Formzahl dilakukan pembuatan kontur. Pada nilai fase dikonversi ke dalam waktu air tinggi (jam) mengacu pada rumus 3. Dengan koordinat Easting, Northing (E, N) lokasi stasiun pasut dan $\mathrm{Z}$ berupa nilai penghitungan analisis konstanta harmonik (amplitudo dan waktu air tinggi). Kontur yang diperoleh di overlay dengan garis pantai dan kedalaman serta dilakukan proses layouting.

\section{HASIL DAN ANALISIS}

Berdasarkan pengolahan data yang telah dilakukan didapatkan peta pasang surut atau Co-Tidal Charts yang terdiri dari Co-Amplitude, Co-Phase dan peta tipe pasut.
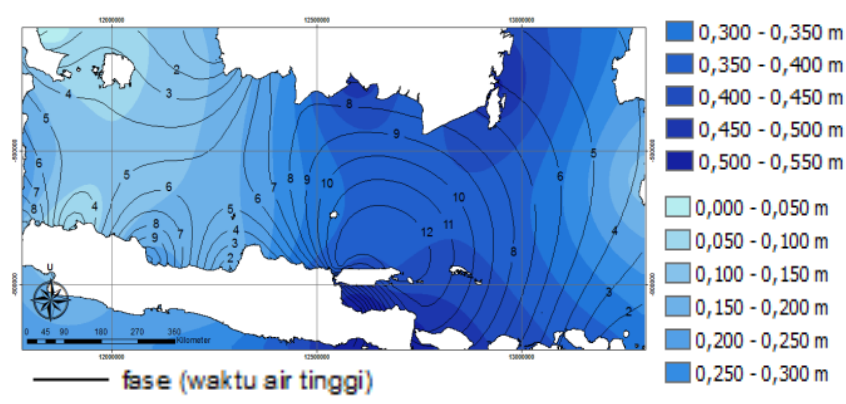

Gambar 3. Konstanta Harmonik $\mathrm{M}_{2}$

Berdasarkan co-tidal charts $\mathrm{M}_{2}$ pada Gambar 3, amplitudo maksimum sebesar 0,550 m . Amplitudo maksimum berada pada perairan selatan Kalimantan dan utara Bali. Nilai amplitudo merambat sesuai dengan perambatan gelombang pasut $\mathbf{M}_{2}$ yakni perambatan gelombang pasut berasal dari Selat Karimata dan perairan selatan Sulawesi menuju tengah Laut Jawa.

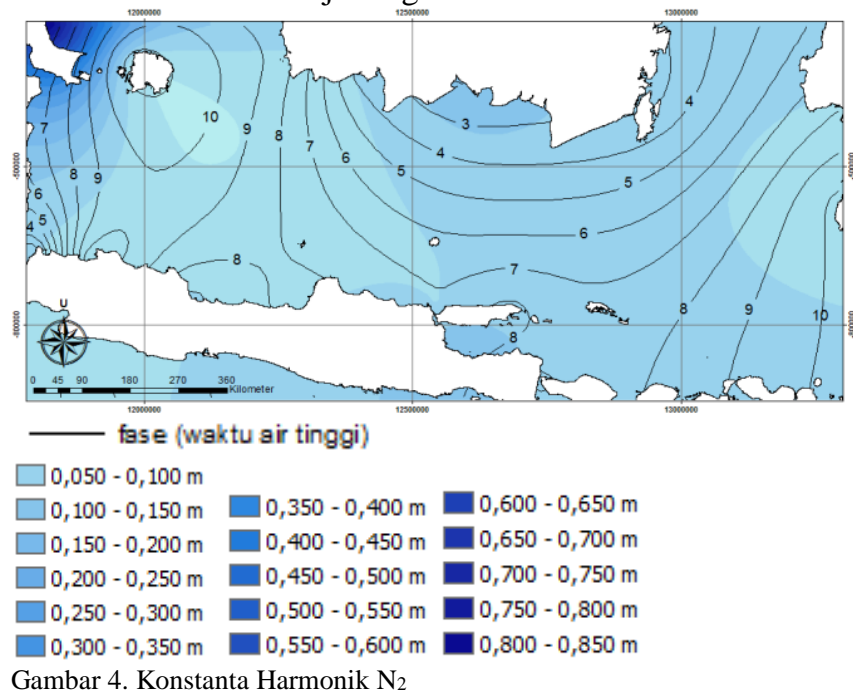

Hasil untuk konstanta $\mathrm{N}_{2}$ pada Gambar 4, nilai amplitudo maksimum berada pada perairan Sumatra atau bagian barat Laut Jawa, ditunjukkan dengan kontur yang cukup rapat dengan nilai $0,850 \mathrm{~m}$. Hal tersebut diakibatkan oleh kedalaman perairan yang dangkal dan penyempitan pada daerah gugusan Pulau [2]. Perambatan gelombang pasutnya berasal dari Selat Malaka, Selat Karimata dan Selat Makasar.

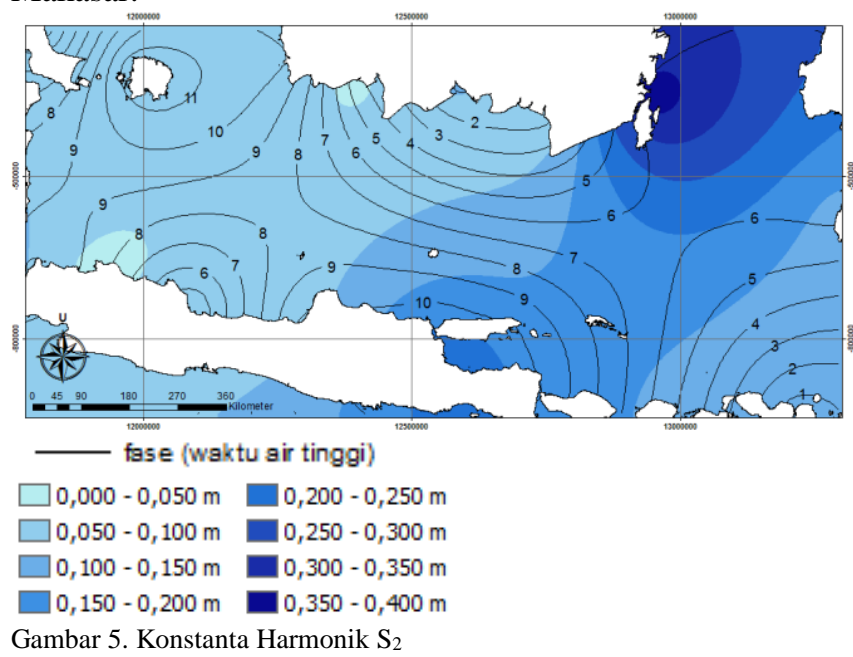


Berdasarkan peta co-tidal charts $\mathrm{S}_{2}$ yang ditunjukkan pada Gambar 5, perambatan gelombang pasut berasal dari Selat Karimata dan Samudra Hindia melalui perairan Nusa Tenggara Barat dan Timur menuju ke tengah Laut Jawa. Nilai amplitudo $S_{2}$ maksimum sebesar $0,400 \mathrm{~m}$ pada perairan Selat Makasar dan minimum pada perairan Selat Karimata dan bagian barat Laut Jawa.

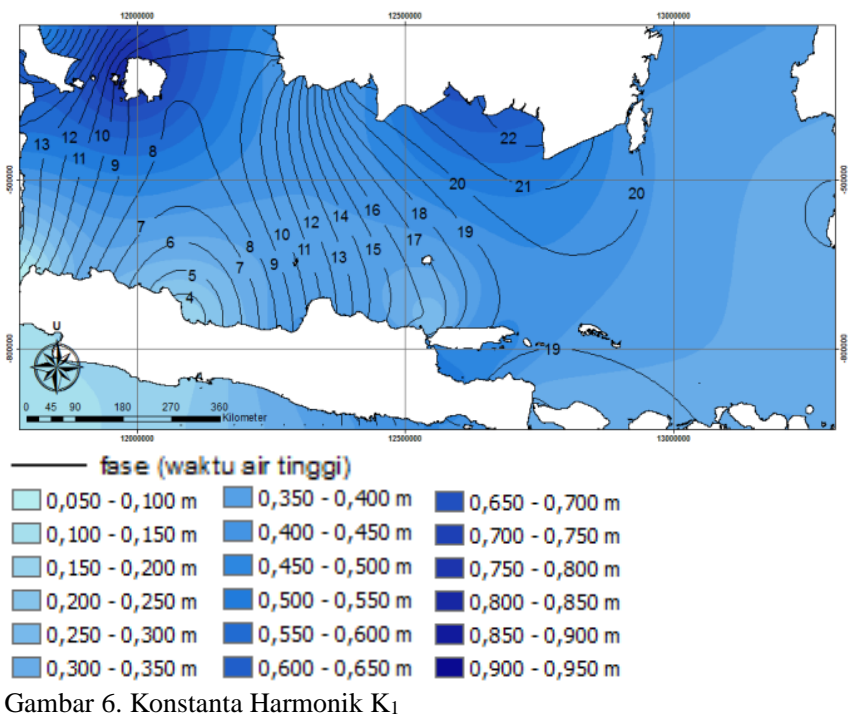

Kontur perambatan gelombang pasut $\mathrm{K}_{1}$ berdasarkan Gambar 6 pada bagian timur Laut Jawa lebih sederhana. Amplitudo maksimum berada pada perairan Selat Karimata sebesar 0,950 m dan amplitudo minimum sebesar 0,050 m pada perairan utara Jawa Barat.

Berdasarkan peta $\mathrm{O}_{1}$ pada Gambar 7, amplitudo maksimum berada pada perairan dangkal Selat Karimata sebesar 0,500 m. Perambatan gelombang pasut berasal dari Selat Karimata menuju ke tengah Laut Jawa dan merambat ke arah barat dan timur. Kontur perambatan pada bagian timur Laut Jawa lebih sederhana seperti perambatan $\mathrm{K}_{1}$. Hal tersebut diakibatkan oleh kedalaman perairan yang dalam [2].

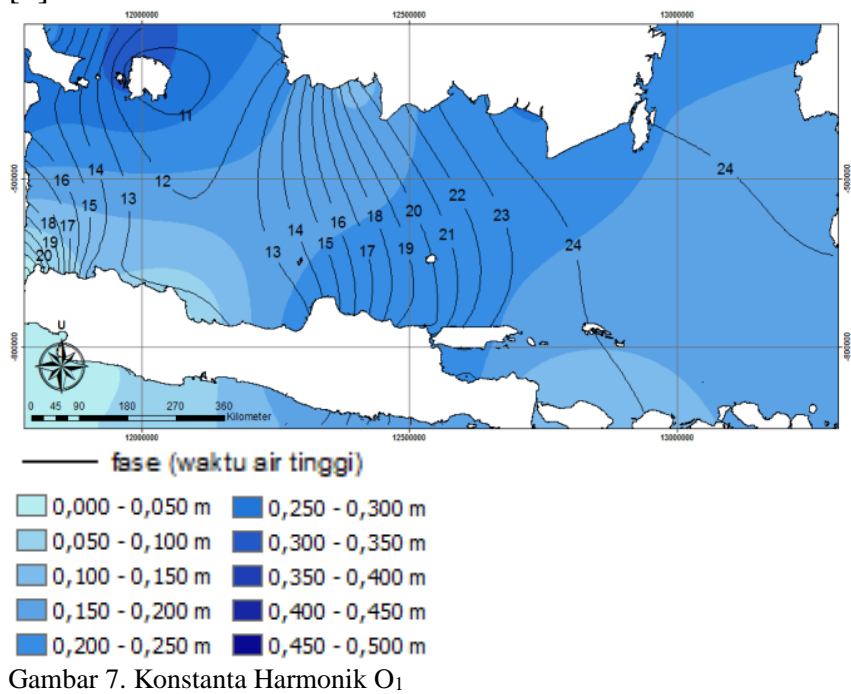

Kondisi amplitudo dan fase yang sangat bervariasi pada perairan Laut Jawa tersebut berkontribusi dalam tipe pasut yang dibentuk. Berdasarkan klasifikasi tipe pasut[3], Laut Jawa mempunyai tiga bentuk tipe pasut yakni diurnal $(F>3)$, campuran dominan diurnal $(1,5<F \leq 3)$ dan campuran dominan semidiurnal $(0,25<F \leq 1,5)$. Dimana tipe diurnal pada area perairan Laut Jawa bagian barat, campuran dominan diurnal meliputi perairan Laut Jawa bagian tengah dan perairan selatan Sulawesi dan tipe campuran dominan diurnal pada perairan laut Jawa bagian timur. Sehingga Perairan Laut Jawa bagian Barat dan Tengah didominasi konstanta harmonik harian (diurnal) dan bagian Timur didominasi konstanta harmonik setengah harian (semidiurnal)[3].

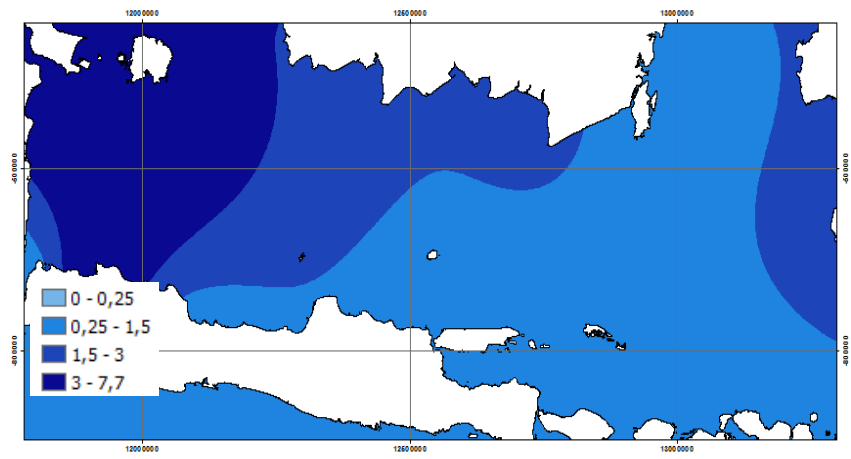

Gambar 8. Tipe Pasut Laut Jawa

\section{KESIMPULAN DAN SARAN}

Berdasarkan penelitian yang telah dilakukan dapat ditarik kesimpulan untuk karakteristik pasang surut Perairan Laut Jawa yakni perambatan gelombang pasut Laut Jawa berasal dari Samudera Hindia dan Laut China Selatan melalui Selat Karimata yang bertemu di tengah Laut Jawa. Perairan Laut Jawa pada bagian Barat dan Tengah didominasi oleh komponen pasut harian (diurnal) dan bagian Timur didominasi komponen pasut setengah harian (semidiurnal).. Kondisi tersebut yang mempengaruhi variasi tipe pasut perairan Laut Jawa dengan tipe diurnal, campuran dominan diurnal dan campuran dominan semidiurnal.

Adapun saran yang dapat diberikan guna penelitian selanjutnya pada bidang ini yakni dapat dilakukan dengan menambahkan konstanta lain seiring dengan penggunaan data pengamatan yang lebih lama, menambahkan data pengamatan pasut pada tengah perairan dari pengamatan satelit Altimetri.

\section{LAMPIRAN}

Tabel 1.

Lokasi Stasiun Pasut

\begin{tabular}{cccc}
\hline \hline No & Stasiun & Easting & Northing \\
\hline 1 & Panjang Lampung & 11724632.602 & -608181.424 \\
2 & Muara Sungai Musi & 11678908.121 & -257539.135 \\
3 & Ciwandan & 11794454.660 & -666747.259 \\
4 & Pangkal Pinang & 11814250.048 & -231966.076 \\
5 & Tanjung Priok & 11898507.462 & -675334.631 \\
6 & Tanjung Pandan & 11981773.513 & -303572.473 \\
7 & Cirebon & 12087434.882 & -746405.730 \\
8 & Semarang & 12292118.648 & -770909.338 \\
9 & Kendawangan & 12269213.116 & -279959.464 \\
10 & Muara Sungai Kotawaringin & 12399599.781 & -323110.882 \\
11 & Teluk Sampit & 12584204.603 & -329415.936 \\
12 & Alur Pelayaran Barat Sby & 12548819.229 & -768113.463 \\
13 & Tanjung Perak & 12547923.726 & -798089.434 \\
14 & Probolinggo & 12603210.551 & -858085.265 \\
15 & Tanjungwangi & 12734925.937 & -901803.904 \\
16 & Muara Sungai Barito & 12748277.164 & -382115.103 \\
17 & Kota baru & 12938963.741 & -357238.172
\end{tabular}




\begin{tabular}{lccr}
18 & Bima & 13215296.442 & -937551.536 \\
19 & Makassar & 13293245.751 & -566015.647 \\
20 & Kalianget & 12684128.379 & -782325.572 \\
\hline
\end{tabular}

\section{UCAPAN TERIMA KASIH}

Penulis mengucapkan terima kasih kepada Pusat HidroOseanografi TNI-AL yang telah memberikan dukungan berupa data pasang surut untuk kebutuhan penelitian sehingga bisa berjalan dengan lancar dan baik.

\section{DAFTAR PUSTAKA}

[1] Ongkosongo, Pasang Surut. Jakarta: Lembaga Ilmu Pengetahuan Indonesia, 1989.

[2] R. S, Teori Umum Pasut. Jakarta: STTAL, 2003.

[3] R. D.R, Tides in Indonesian Seas. J. Oceanogr. 2005. 